\title{
Substituição Parcial e Total da Proteína do Farelo de Soja pela Proteína do Farelo de Canola na Alimentação de Alevinos de Piavuçu (Leporinus macrocephalus, L.) ${ }^{1}$
}

\section{Claudemir Martins Soares ${ }^{2}$, Carmino Hayashi ${ }^{3}$, Valéria Rossetto Barriviera Furuya ${ }^{4}$, Wilson Massamitu Furuya ${ }^{5}$, Eliana Maria Galdioli ${ }^{2}$}

\begin{abstract}
RESUMO - O objetivo deste trabalho foi avaliar os efeitos da substituição da proteína do farelo de soja (FS) pela proteína do farelo de canola (FC) em dietas para alevinos de piavuçu (Leporinus macrocephalus). Um total de 288 alevinos com, em média, $0,17 \pm 0,03 \mathrm{~g}$ PV inicial e comprimento total inicial de $2,95 \pm 0,19 \mathrm{~cm}$, foi distribuído em 24 aquários $(50 \mathrm{~L}) \mathrm{com} 12$ peixes em cada em um delineamento inteiramente casualizado com seis tratamentos $(0,0 ; 20,0 ; 40,0 ; 60,0 ; 80,0 ;$ e 100,0\%), que correspondeu, respectivamente, a 0,$00 ; 8,03 ; 16,10 ; 24 ; 10$; 32,15; e 43,12\% de inclusão de FC nas dietas, com quatro repetições. As dietas, formuladas de modo a serem isoprotéicas, isocálcicas e isofosfóricas, foram fornecidas durante 28 dias. A taxa de eficiência protéica e a sobrevivência não foram influenciadas pelos níveis de substituição da proteína do FS pela do FC. Entretanto, foram observados efeitos lineares para porcentagem de ganho de peso, porcentagem de incremento em comprimento e custo da dieta/kg ganho e efeito quadrático dos níveis de substituição da proteína do farelo de soja sobre a conversão alimentar. A substituição de 100,00\% da proteína do FS pela do FC ou a inclusão de 43,12\% do FC nas dietas resultou em melhor desempenho de alevinos de piavuçu.
\end{abstract}

Palavras-chave: alevinos, farelo de canola, Leporinus macrocephalus, piavuçu

\section{Partial and Total Replacement of Soybean Meal Protein by Canola Meal Protein in Piavuçu (Leporinus macrocephalus, L.) Fry Diets}

\begin{abstract}
The objective of this work was to evaluate the effects of the replacement of the protein from soybean meal (SM) by protein from canola meal (CM) in diets for piavuçu fry (Leporinus macrocephalus). Two hundred and eighty-eight fry with initial $0.17 \pm .03 \mathrm{~g} \mathrm{LW}$ and length of $2.95 \pm .19 \mathrm{~cm}$ were allotted to 24 aquarium, (50-L) with 12 fish in each one. A completely randomized design with six treatments $(0,20.0,40.0,60.0,80.0$, and $100.0 \%$, which corresponded to $0.0,8.03,16.10,24.10,32.15$, and $43.12 \%$ of the $\mathrm{CM}$ inclusion in the diets and four replicates, was used. The diets, formulated to be isonitrogenous, isocalcium and isophosphoric were fed during 28 days. The protein efficiency and survival rate were not affect by the replacement levels from SM protein by CM protein. However, linear effects were observed for the percentage of weight gain, percentage of length increase and cost of the diet $/ \mathrm{kg}$ gain and a quadratic effect of the replacement levels of protein from soybean meal on feed:gain ratio. The replacement of $100.0 \%$ of the protein from SM by CM protein or the inclusion of $43.12 \%$ of CM in the diet produced a better performance of the piavuçu fry.
\end{abstract}

Key Words: fry, canola meal, Leporinus macrocephalus, piavuçu

\section{Introdução}

Entre as espécies nativas de peixes do Brasil, algumas apresentam grande potencial para a piscicultura, por apresentarem crescimento rápido, carne saborosa e rusticidade e aceitarem dietas artificiais.

O gênero Leporinus, caracterizado como de hábito alimentar onívoro, pode utilizar ampla gama de alimentos, sendo que vegetais e sementes são itens freqüentes em sua dieta (SILVA, 1988; ANDRIAN et al., 1994). Pertencente à família Anostomidae, ainda é praticamente desconhecido do ponto de vista zootécnico (CASTAGNOLLI, 1992), tendo atualmente algumas de suas espécies (L. elongatus, $L$. friderice, L. obtusidens e L. macrocephalus) utilizadas para piscicultura. São poucos os trabalhos visando determinar seus desempenhos, necessidades nutricionais e utilização de alimentos alternativos (ZANIBONI et al., 1988; BARBOSA et al., 1996; e FURUYA et al., 1996).

Recentemente, com a expansão da atividade de "pesque-pague", têm-se buscado espécies que se adaptem à pesca esportiva, na qual se destaca o piavuçu.

\footnotetext{
${ }^{1}$ Parte da Dissertação de Mestrado em Zootecnia, apresentada à Universidade Estadual de Maringá - UEM pelo primeiro autor.

2 Biólogo - Departamento de Biologia/UEM. E.mail: cmsoares@uem.br; emgaldioli@uem.br

3 Professor Titular - Departamento de Biologia/UEM. E.mail: chayashi@uem.br

${ }^{4}$ Curso de Pós-Graduação em Ecologia em Ambientes Aquáticos Continentais/PEA/DBI/UEM. E.mail: furuya@wnet.com.br

${ }^{5}$ Professor - Departamento de Zootecnia/UEM. E.mail: furuya@wnet.com.br
} 
A canola - planta oleaginosa resultante do melhoramento genético da colza (Brassica napus e $B$. campestris), visando produzir variedades que contenham menos de $2,00 \%$ de ácido erúcico no óleo e menos de 3,00 $\mu \mathrm{g}$ de glicosinolatos por grama de matéria seca livre de óleo (HIGGS et al., 1982; SORREL e SHURSON, 1992; e TESKEREDIZIC et al., 1995) - tem sido cultivada na região sul do Brasil como planta de inverno, sendo que, atualmente, o farelo de canola (FC) apresenta preço inferior ao farelo de soja (FS), oscilando em cerca de $70 \%$ do custo deste.

Os custos com a alimentação corresponde à maior parte dos custos totais de produção na piscicultura semi-intensiva (MEER et al., 1995), uma vez que as dietas de peixes, em comparação à de outros animais, caracterizam-se pelo elevado nível protéico, sendo que a maior parcela dos custos das dietas é atribuída à fonte de proteína. Entre as fontes protéicas mais utilizadas, estão a farinha de peixe (FP) e o farelo de soja, entretanto, têm-se buscado outras fontes de menor custo que não influam no desempenho dos animais, reduzindo os custos de produção. $\mathrm{O}$ FC, que possui alto teor de proteína e perfil de aminoácidos similar ao do FS (YURKOWSKI et al. 1978; MOREIRA et al., 1996), porém com níveis mais baixos de lisina e mais elevados de metionina + cistina (MURAKAMI et al., 1995) (Tabela 1), é um subproduto da indústria de óleo que tem sido testado na alimentação de diferentes espécies.

Existem ainda alguns fatores que limitam a inclusão do FC em dietas para monogástricos, como alto nível de fibra (SARWAR et al., 1981; HIGGS et al., 1982), níveis tóxicos de metabólitos oriundos da hidrólise dos glicosinolatos e teores de ácidos erúcicos e inibidores de tripsina, fitatos, compostos fenólicos e taninos (YURKOWSKI et al., 1978; BELL, 1993; e TESKEREDIZIC et al., 1995). Os avanços no melhoramento genético em relação a esta planta e o uso de modernas técnicas de processamento têm aumentado a disponibilidade de seus nutrientes e eliminado substâncias tóxicas, melhorando o valor nutritivo de seus produtos e subprodutos para serem utilizados na alimentação animal e humana (YURKOWSKI et al., 1978; HIGGS et al., 1982; HARDY e SULLIVAN, 1983; BAIDOO et al., 1996; e SCHÖNE et al., 1996).

A substituição total de FS por FC, no nível de $22,00 \%$ de uma dieta contendo FP para alevinos de truta arco-íris (Oncorhynchus mykiss) com 4,25 g, proporcionou melhoras no ganho de peso e na conversão alimentar (YURKOWSKI et al., 1978). Tra- balhando com a mesma espécie, porém com peso inicial de 105 g, HARDY e SULLIVAN (1983) observaram que o fornecimento de dietas com $20,00 \%$ de inclusão de FC, em substituição à FP, não influiu no desempenho dos peixes. Por outro lado, HILTON e SLINGER (1986) observaram que a inclusão de $40,00 \%$ de FC em dietas práticas para S. gairdneri, com peso inicial médio de $2,00 \mathrm{~g}$, prejudicou o peso final, embora a conversão alimentar e a sobrevivência não tenham sido influenciadas.

Estudando os efeitos de diferentes níveis de inclusão de $\mathrm{FC}(0,00 ; 11,50 ;$ e 23,00\%), em substituição à FP, para alevinos de salmão (O. tshawytscha), HIGGS et al. (1983) concluíram que o FC pode substituir cerca de $25,00 \%$ da proteína das dietas para essa espécie.

CAPPER et al. (1982), utilizando farelo de colza cru e tostado, incluídos a 20,00\% em dietas para alevinos de carpa comum (Cyprinus carpio), em substituição ao FS, não constataram declínio significativo na taxa de crescimento e na conversão alimentar. DAVIES et al. (1990) avaliaram níveis crescente de inclusão de $\mathrm{FC}(0,00 ; 15,00 ; 30,00 ; 45,00 ; \mathrm{e} 60,00 \%)$, em substituição à FP, em dietas para alevinos de tilápia (Oreochromis mossambicus), revertidos sexualmente, com peso de $0,30 \mathrm{~g}$, ressaltando que o FC pode ser incluído em até $15,00 \%$ da dieta para esta espécie. FURUYA et al. (1997) indicam que o FC pode ser incluído no nível de 19,70\% da dieta, ou substituir $35,89 \%$ da proteína do FS para tilápia do Nilo (Oreochromis niloticus), durante o período de reversão de sexo, sendo que estes níveis levam a melhores índices de ganho de peso, comprimento total, conversão alimentar, taxa de eficiência protéica e custo por $\mathrm{kg} / \mathrm{ganhho}$. Esses autores observaram, ainda, que todos os níveis de inclusão testados levaram a melhores resultados, quando comparados com o desempenho de peixes alimentados com a dieta contendo somente FS.

LIM et al. (1998), avaliando a inclusão de FC em dietas nos níveis de 0,$00 ; 15,40 ; 30,80 ; 46,20$; e $61,60 \%$, observaram que a inclusão até $30,80 \%$ de FC não influiu no ganho de peso, na utilização do alimento e na taxa de sobrevivência de "catfish" (Ictalurus punctatus), entretanto, a inclusão de maiores níveis levou à redução do ganho de peso. SOARES et al. (1998), realizando a substituição da proteína do FS pela do FC a níveis de 0,$00 ; 20,00 ; 40,00 ; 60,00$; e $80,00 \%$, em dieta para alevinos de carpa-capim (Ctenopharyngodon idella), observaram efeito quadrático dos níveis de substituição sobre o peso final e comprimento final médios com valores máxi- 
Rev. bras. zootec.

mos a 35,79 e 37,27\% de substituição ou inclusão de 14,40 e 14,97\% de FC, respectivamente, apesar de a conversão alimentar e as taxas de eficiência protéica e sobrevivência não terem sido influenciadas.

Em relação às espécies utilizadas pela piscicultura em condições tropicais, existem poucos pesquisadores que tenham se voltado para o estudo do FC como fonte protéica, sendo que para espécies nativas estes trabalhos são inexistentes, o que ressalta a importância de estudos para reduzir os custos com a alimentação. Este experimento foi conduzido com o objetivo de estudar a influência de níveis crescentes de substituição da proteína do farelo de soja pela proteína do farelo de canola sobre o desempenho de alevinos de piavuçu (Leporinus macrocephalus).

\section{Material e Métodos}

O experimento foi realizado no Laboratório de Aqüicultura do Centro de Ciências Biológicas da Universidade Estadual de Maringá, no período de 17 de março a 19 de abril de 1996.

Foram utilizados 288 alevinos de piavuçu com, em média, peso vivo inicial de $0,17 \pm 0,03 \mathrm{~g}$ e comprimento total inicial de 2,95 $\pm 0,19 \mathrm{~cm}$, provenientes de reprodução induzida, sendo que a fase de larvicultura foi realizada no Laboratório de Aqüicultura. Os alevinos foram distribuídos em 24 aquários, com capacidade individual para $50 \ell$, providos de aeração constante por intermédio de compressores portáteis. Foi usado delineamento experimental inteiramente casualizado com seis tratamentos e quatro repetições, sendo a unidade experimental constituída por um aquário com 12 alevinos. A fase de adaptação durou cinco dias e, nesse período, os peixes foram alimentados com a dieta controle.

As dietas foram fornecidas duas vezes ao dia, na proporção de $15,00 \%$ do peso vivo/dia, e a quantidade a ser fornecida em cada aquário foi umedecida até adquirir aspecto pastoso. Para correção da quantidade de ração a ser fornecida, todos os indivíduos de cada aquário foram pesados semanalmente. Diariamente $(8 \mathrm{~h})$, os aquários foram sifonados para retirar as sobras e fezes, sendo retirados $20,00 \%$ do volume d'água, o qual era reposto.

As dietas experimentais, isoprotéicas, isocálcicas e isofosfóricas, foram formuladas para terem diferentes níveis de substituição da proteína do FS pela proteína do FC $(0,00 ; 20,00 ; 40,00 ; 60,00 ; 80,00$; e $100,00 \%)$, o que correspondeu, respectivamente, a níveis de 0,$00 ; 8,03 ; 16,10 ; 24,10 ; 32,15 ;$ e $43,13 \%$ de inclusão do FC nas dietas (Tabela 2). Apesar de não ter sido incluído óleo nas dietas, os valores de ácido linoléico apresentaram-se acima dos recomendados pelo NATIONAL RESEARCH COUNCIL - NRC (1993) para tilápias. Para a elaboração das dietas experimentais, os alimentos (FS, FC, FP, milho e calcário) foram moídos individualmente para que as partículas tivessem tamanhos similares $(<1 \mathrm{~mm})$. Os parâmetros físico-químicos da água - pH, condutividade elétrica e oxigênio dissolvido - foram medidos semanalmente, enquanto a temperatura foi tomada diariamente de manhã (8 h) e à tarde (16h30).

Ao final do período experimental, foram tomadas as medidas individuais de peso $(\mathrm{g})$ e comprimento total $(\mathrm{cm})$ dos peixes de cada unidade experimental. As variáveis avaliadas foram peso final, porcentagem de ganho de peso, porcentagem de incremento em comprimento total, conversão alimentar, sobrevivência, taxa de eficiência protéica e viabilidade econômica.

A taxa de eficiência protéica, porcentagem de ganho de peso e porcentagem de incremento em comprimento, nos diferentes tratamentos, foram calculadas

Tabela 1 - Composição percentual dos ingredientes do farelo de soja e do farelo de canola (matéria natural) ${ }^{1}$

Table 1 - Percentage composition of the ingredients of soybean meal and canola meal (as fed)

$\begin{array}{lll}\text { Ingrediente }(\%) & \text { Farelo de canola }^{1} & \text { Farelo de soja } \\ & \end{array}$

$\begin{array}{lll}\text { Ingredient } & \text { Canola meal } & \text { Soybean meal } \\ \end{array}$

\begin{tabular}{lll}
\hline Matéria seca & 93,00 & 88,60
\end{tabular}

Dry matter

Proteína bruta $\quad 38,92 \quad 45,60$

Crude protein

Extrato etéreo

45,60

Ether extract

Linoléico ${ }^{4}$

$2,15^{3}$

0,79

Linoleic $^{4}$

Fibra bruta

Crude fiber

Matéria mineral $\quad 6,80^{5} \quad 6,01$

Ash

Cálcio

$0,43 \quad 0,40$

Calcium

Fósforo

Phosphorus

Lisina

Lysine

Metionina

0,43

0,40

11,10

6,46

Methionine

Met.+cistina

0,68

0,36

Methionine + cystine

${ }^{1}$ NERILO et al. (1996), ${ }^{2}$ ROSTAGNO et al. (1994), ${ }^{3}$ SCAPINELLO et al. (1994), ${ }^{4}$ NRC (1993), ${ }^{5}$ SORREL e SHURSON (1992). 
segundo as expressões de JAUNCEY e ROSS (1982). Para avaliar a viabilidade econômica da substituição da proteína do farelo de soja pela proteína do farelo de canola, em dietas para alevinos de piavuçu, foi determinado o custo médio das dietas por quilograma de peso vivo ganho, de acordo com BELLAVER et al. (1985).

O modelo estatístico utilizado para as análises das variáveis estudadas foi:

em que

$$
Y_{i j}=\mu+b_{1}\left(n_{i}-n\right)+b_{2}\left(n_{i}-n\right)^{2}+e_{i j}
$$

$\mathrm{Y}_{\mathrm{ij}}=$ observação referente ao aquário $\mathrm{j}$ onde se utilizou o nível de substituição i;

$\mu=$ constante geral;

$\mathrm{b}_{1}=$ coeficiente linear de regressão da variável

Y, em função do nível de substituição i;

$\mathrm{b}_{2}=$ coeficiente quadrático de regressão da variável $\mathrm{Y}$, em função do nível de substituição i; $\mathrm{n}_{\mathrm{i}}=$ nível de substituição i;

$\mathrm{n}$ = média dos níveis de substituição; e

$\mathrm{e}_{\mathrm{ij}}=$ desvio aleatório associado a cada observação $Y_{i j}$.

Para a análise estatística, os dados foram submetidos a análises de variância e regressão, por intermédio do programa estatístico SAEG (Sistema de Análises Estatísticas e Genéticas) descrito por EUCLYDES (1983), em nível de 5\% de probabilidade.

\section{Resultados e Discussão}

Na Tabela 3, encontram-se os resultados médios para peso final, ganho de peso, porcentagem de ganho de peso, porcentagem de incremento em comprimento total, taxa de eficiência

Tabela 2 - Composição percentual e química das dietas experimentais com níveis crescentes de substituição da proteína do farelo de soja pela do farelo de canola (matéria natural) ${ }^{1}$

Table 2 - Chemical and percentage composition of experimental diets with increasing replacement levels of soybean meal protein by canola meal protein (as fed)

\begin{tabular}{|c|c|c|c|c|c|c|}
\hline \multirow[t]{2}{*}{$\begin{array}{l}\text { Ingrediente }(\%) \\
\text { Ingredient }\end{array}$} & \multicolumn{6}{|c|}{$\begin{array}{l}\text { Nível de substituição (\%) } \\
\text { Substitution level }\end{array}$} \\
\hline & 0 & 20 & 40 & 60 & 80 & 100 \\
\hline Milho (Corn) & 55,50 & 53,69 & 51,85 & 50,04 & 48,22 & 45,62 \\
\hline Farelo de soja (Soybean meal) & 32,62 & 26,54 & 20,44 & 14,39 & 8,30 & 0,00 \\
\hline Farelo de canola (Canola meal) & 0,00 & 8,03 & 16,10 & 24,10 & 32,15 & 43,12 \\
\hline Farinha peixe (Fish meal) & 10,00 & 10,00 & 10,00 & 10,00 & 10,00 & 10,00 \\
\hline Calcário (Limestone) & 0,04 & 0,10 & 0,16 & 0,22 & 0,28 & 0,19 \\
\hline Fosfato bicálcico (Dicalcium phosphate) & 0,82 & 0,63 & 0,43 & 0,24 & 0,04 & 0,05 \\
\hline Premix min. e vitam. (Min. vitam. mix) & 0,50 & 0,50 & 0,50 & 0,50 & 0,50 & 0,50 \\
\hline Sal (Salt) & 0,50 & 0,50 & 0,50 & 0,50 & 0,50 & 0,50 \\
\hline BHT & 0,02 & 0,02 & 0,02 & 0,02 & 0,02 & 0,02 \\
\hline \multicolumn{7}{|l|}{ Valores calculados } \\
\hline $\begin{array}{l}\text { Energia digestível/peixes }(\mathrm{kcal} / \mathrm{kg})^{2} \\
\text { Digestible energy } / \text { fish }(\text { kcal } / \mathrm{kg})^{2}\end{array}$ & $2.517,21$ & $2.529,86$ & $2.536,04$ & $2.539,08$ & $2.548,29$ & $2.552,74$ \\
\hline Proteína bruta (Crude protein), \% & 26,00 & 26,00 & 26,00 & 26,00 & 26,00 & 26,00 \\
\hline Extrato etéreo (Ether extract), \% & 2,78 & 2,84 & 2,91 & 2,97 & 3,04 & 3,12 \\
\hline Linoléico $\left(\right.$ Linoleic) ${ }^{3}, \%$ & 1,20 & 1,18 & 1,15 & 1,13 & 1,10 & 1,03 \\
\hline Fibra bruta (Crude fiber), $\%$ & 3,10 & 3,59 & 4,09 & 4,58 & 5,07 & 5,74 \\
\hline Lisina (Lysine), \% & 1,61 & 1,62 & 1,62 & 1,62 & 1,63 & 1,63 \\
\hline Met+cistina (Methionine + Cystine), $\%$ & 0,90 & 0,87 & 0,84 & 0,80 & 0,76 & 0,72 \\
\hline Cálcio $($ Calcium $)(\%)$ & 0,92 & 0,92 & 0,92 & 0,92 & 0,92 & 0,92 \\
\hline $\mathrm{P}$ total (Total P), \% & 0,80 & 0,80 & 0,80 & 0,80 & 0,80 & 0,80 \\
\hline $\mathrm{R} \$ / \mathrm{kg}$ de $\operatorname{dieta}^{4}(R \$ / \mathrm{kg}$ diet $)$ & 0,21 & 0,21 & 0,21 & 0,20 & 0,19 & 0,19 \\
\hline \multicolumn{7}{|c|}{1 Com base nas análises de laboratório realizadas para o milho, farelo de soja farinha de peixe, farelo de canola, calcário e fosfato bicálcico } \\
\hline 2 Com base nos valores de energia digestível pr & tos pelo $\mathrm{NR}$ & (1993) para & ápia para mi & $3020 \mathrm{kcal} / \mathrm{kg}$ & $\begin{array}{l}\text { arinha de pe } \\
\mathrm{kcal} / \mathrm{kg} \text {, pa }\end{array}$ & $\begin{array}{l}4040 \mathrm{kcal} / \mathrm{kg} \text {; } \\
\text { ruta arco-íris. }\end{array}$ \\
\hline \multicolumn{7}{|c|}{$\begin{array}{l}4 \text { Farinha de peixe: } R \$ 400,00 / t \text {, farelo de soja: } R \$ 307,50 / t \text {, farelo de canola: } R \$ 216,00 / t \text {, milho: } R \$ 116,67 / t \text {, calcário: } R \$ 250,00 / t \text {, fosfato } \\
\text { bicálcico: } R \$ 830,00 / t \text {, sal: } R \$ 150,00 / t \text {, premix: } R \$ 1300,00 / t \text { (Obtenção dos preços: } 15 / 02 / 1997) \text {. }\end{array}$} \\
\hline \multicolumn{7}{|c|}{1 Based on laboratory analyses, made to corn, soybean meal, fish meal, canola meal, limestone and dicalcium phosphate (UEM/DZO). } \\
\hline \multirow{2}{*}{\multicolumn{7}{|c|}{$\begin{array}{l}2 \text { Based on proposed digestible energy values, for tilapia, for corn: } 3020 \mathrm{kcal} / \mathrm{kg} \text {, fish meal: } 4040 \mathrm{kcal} / \mathrm{kg} \text { by NRC (1993) and for soybean meal: } 2600 \mathrm{kcal} / \mathrm{kg} \\
\text { by PEZZATO (1995); and for canola meal: } 2725 \mathrm{kcal} / \mathrm{kg} \text { for rainbow trout by NRC (1995). } \\
3 \text { Based on proposed values for fish, soybean, canola and corn oils by NRC (1993). }\end{array}$}} \\
\hline & & & & & & \\
\hline \multicolumn{7}{|l|}{ 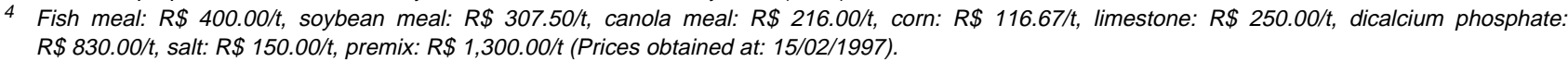 } \\
\hline
\end{tabular}


Rev. bras. zootec.

protéica, conversão alimentar, sobrevivência e custo das dieta por quilograma de ganho de peso $(\mathrm{R} \$ / \mathrm{kg}$ ganho) de alevinos de piavuçu (L. macrocephalus) submetidos a dietas com níveis crescentes de substituição da proteína do FS pela proteína do FC, ao final de 28 dias de experimento.

Não houve efeito $(\mathrm{P}>0,05)$ dos níveis de substituição da proteína do FS pela proteína do FC sobre a taxa de eficiência protéica e sobrevivência. Estes resultados assemelham-se aos obtidos, para carpacapim, por SOARES et al. (1998); truta arco-íris, HILTON e SLINGER (1986); e de HIGGS et al. (1982), para salmão, no que se refere à taxa de eficiência protéica, entretanto, diferem dos encontrados por DAVIES et al. (1990), os quais observaram valores mais elevados para tilápia moçambica, e FURUYA et al. (1997), que observaram efeito quadrático para este parâmetro em $O$. niloticus. Os dados de sobrevivência estão de acordo com os obtidos por HIGGS et al. (1982) e HIGGS et al. (1983), para salmão; HILTON e SLINGER (1986), para truta arco-íris; FURUYA et al. (1997) para O. niloticus; e SOARES et al. (1998), para carpa-capim.

O aumento na substituição da proteína do FS pela proteína do FC elevou linearmente a porcentagem de ganho de peso (Figura 1), discordando dos dados de HARDY e SULLIVAN (1983), para truta arco-íris, que não verificaram diferença, devido à inclusão de FC, e DAVIES et al. (1990), que observaram redução com a inclusão de FC, para tilápia moçambica. Do mesmo modo, a porcentagem de incremento em comprimento também melhorou linearmente $(\mathrm{P}<0,05)$ ( $\hat{Y}=27,88560+0,05929 X)$ com o aumento do nível de

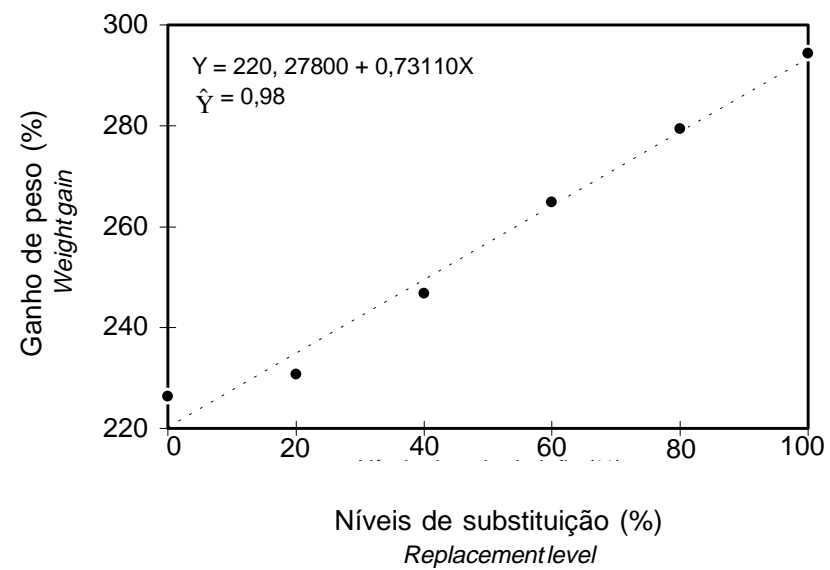

Figura 1 - Efeito dos níveis de substituição da proteína na dieta sobre a porcentagem de ganho de peso de alevinos de piavuçu.

Figure 1 - Effect of the dietary protein replacement level on the percentage of weight gain rate of piavuçu fry. substituição da proteína do FS pela proteína do FC.

Verificou-se efeito quadrático $(\mathrm{P}<0,05)$ dos níveis de substituição da proteína do FS pela proteína do FC sobre a conversão alimentar, atingindo o melhor valor no nível de $90,24 \%$ de substituição ou $37,77 \%$ de inclusão na dieta (Figura 2). Estes resultados diferem dos encontrados por CAPPER et al. (1982), para carpa comum; HIGGS et al. (1983), para salmão; HILTON e SLINGER (1986), para truta arco-íris; e SOARES et al., para carpa-capim, que não observaram efeito da inclusão de FC nas dietas sobre a conversão alimentar. DAVIES et al. (1990), trabalhando com $O$. mossambicus, e HIGGS et al. (1982) observaram piora na conversão alimentar com a inclusão de FC. Por outro lado, FURUYA et al. (1997), trabalhando com tilápias, observaram efeito quadrático dos níveis de substituição da proteína do FS pela proteína do FC, durante o período de reversão de sexo, entretanto, o melhor nível de substituição foi de $35,89 \%$, o qual é inferior ao obtido neste trabalho. YURKOWSKI et al. (1978) também observaram melhora na conversão alimentar de truta arco-íris com adição de FC na dieta, estando de acordo com os resultados deste trabalho.

Quanto à analise de custo (R $\$ / \mathrm{kg}$ ganho de peso), ocorreu redução linear $(\mathrm{P}<0,05)$, indicando que a substituição total de proteína do FS pela proteína do FC nas dietas proporcionou redução dos custos de produção desta espécie (Figura 3). Este dado discorda do obtido por FURUYA et al. (1997), para O niloticus, que observaram efeito quadrático para esta característica, com diminuição dos custos até o nível de $25,36 \%$ de substituição da proteína do FS pela proteína do FC.

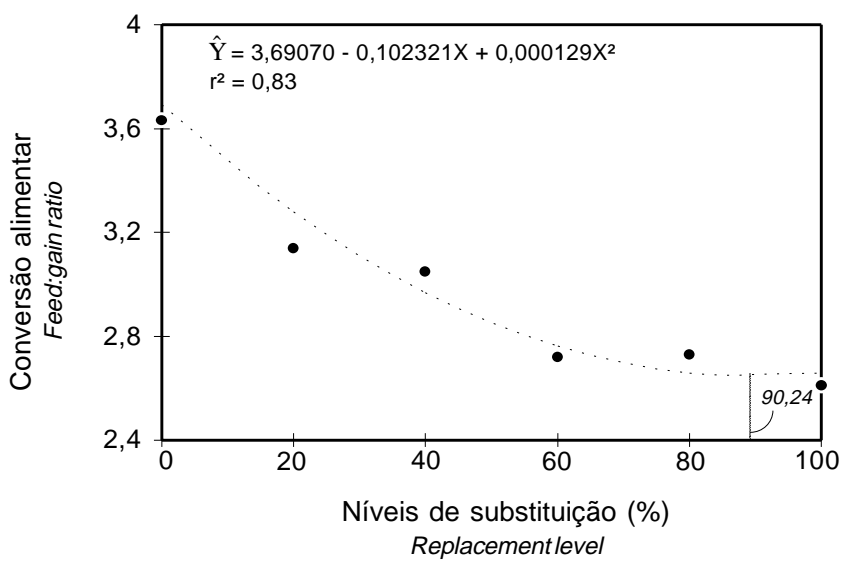

Figura 2 - Efeito dos níveis de substituição da proteína na dieta sobre a conversão alimentar de alevinos de piavuçu.

Figure 2 - Effect of the dietary protein replacement level on the feed:gain ratio of piavuçu fry. 
De modo geral, a substituição da proteína do FS pela proteína do FC, nas dietas para piavuçu, melhorou as características avaliadas, mesmo quando comparado aos resultados obtidos com outras espécies. Dessa forma, a proteína do FC pode substituir totalmente a proteína do FS ou o FC pode ser incluído no nível de $43,12 \%$ em dietas para alevinos de piavuçu. Estes valores são superiores aos propostos por YURKOWSKI et al. (1978), que previram a inclusão de 25,00\% de FC nas dietas para alevinos de salmão, e HARDY e SULLIVAN (1983), HIGGS et al. (1983), de 22,00 e 20,00\%, respectivamente, em dietas para truta arco-íris, entretanto estas espécies são de hábito alimentar carnívoro, enquanto o piavuçu, segundo ANDRIAN et al. (1994), é omnívoro, tendo vegetais como parte significativa de sua dieta. DAVIES et al. (1990) propuseram uso de $15,00 \%$ de FC na dieta para $O$. mossambicus, ao passo que FURUYA et al. (1997) sugeriram a inclusão de $19,70 \%$ ou substituição de $35,89 \%$ da proteína do FS pela proteína do FC, em dietas para $O$. niloticus, e SOARES et al. (1998), a inclusão de $14,40 \%$ ou substituição de $37,79 \%$ da proteína do FS pela do FC.

Os valores médios de $\mathrm{pH}$, oxigênio dissolvido

Tabela 3 - Valores médios de desempenho e custo por quilograma ganho de alevinos de piavuçu submetidos a dietas com níveis crescentes de substituição da proteína do farelo de soja pela proteína do farelo de canola

Table 3 - Average performance values and cost of diet by kilogram gain of piavuçu fry fed diets with different replacement levels of soybean meal protein by canola meal protein

\begin{tabular}{|c|c|c|c|c|c|c|c|}
\hline \multirow{3}{*}{$\begin{array}{l}\text { Variável } \\
\text { Variable }\end{array}$} & \multirow{2}{*}{\multicolumn{6}{|c|}{ Níveis de substituição (\%) }} & \multirow[b]{3}{*}{$\mathrm{CV}(\%)$} \\
\hline & & & & & & & \\
\hline & 0 & 20 & 40 & 60 & 80 & 100 & \\
\hline Peso inicial (g) & 0,17 & 0,17 & 0,17 & 0,17 & 0,17 & 0,17 & 19,53 \\
\hline Initial weight & & & & & & & \\
\hline Ganho de peso $(\%)^{1}$ & 226,29 & 230,79 & 246,82 & 264,85 & 279,34 & 294,41 & 21,10 \\
\hline Weight gain & & & & & & & \\
\hline $\begin{array}{l}\text { Comprimento inicial }(\mathrm{cm}) \\
\text { Initial length }\end{array}$ & 2,95 & 2,95 & 2,95 & 2,95 & 2,95 & 2,95 & 3,90 \\
\hline $\begin{array}{l}\text { Incremento comprimento }(\%)^{1} \\
\text { Length increase }\end{array}$ & 28,48 & 28,30 & 29,60 & 33,29 & 31,78 & 33,80 & 13,52 \\
\hline $\begin{array}{l}\text { Taxa de eficiência protéica } \\
\text { Protein efficiency rate }\end{array}$ & 1,26 & 1,26 & 1,28 & 1,44 & 1,44 & 1,47 & 13,31 \\
\hline Sobrevivência (\%) & 100,00 & 100,00 & 100,00 & 100,00 & 100,00 & 100,00 & 0,00 \\
\hline $\begin{array}{l}\text { Survival rate } \\
\mathrm{R} \$ / \mathrm{kg}_{\text {ganho }}{ }^{1} \\
R \$ / \mathrm{kg} \text { gin }^{1}\end{array}$ & 0,65 & 0,70 & 0,64 & 0,58 & 0,55 & 0,52 & 16,78 \\
\hline
\end{tabular}

1 Efeito linear $(\mathrm{P}<0,05)$.

2 Efeito quadrático $(P<0,05)$

1 Linear effect $(\mathrm{P}<.05)$.

2 Quadratic effect $(P<.05)$.

Tabela 4 - Valores médios de pH, oxigênio dissolvido, temperaturas pela manhã e tarde e condutividade elétrica da água dos diferentes tratamentos para piavuçu

Table 4 - Average values of water $\mathrm{pH}$, dissolved oxygen, temperature by morning and afternoon and electric conductivity in different treatments to piavuçu fry

\begin{tabular}{|c|c|c|c|c|c|c|}
\hline \multirow{3}{*}{$\begin{array}{l}\text { Variável } \\
\text { Variable }\end{array}$} & \multicolumn{6}{|c|}{ Níveis de substituição (\%) } \\
\hline & \multicolumn{6}{|c|}{ Substitution level } \\
\hline & 0 & 20 & 40 & 60 & 80 & 100 \\
\hline$\overline{\mathrm{pH}}$ & 7,33 & 7,36 & 7,34 & 7,36 & 7,36 & 7,33 \\
\hline Oxigênio dissolvido $(\mathrm{mg} / \ell)$ & 8,83 & 8,81 & 8,69 & 8,79 & 8,70 & 8,68 \\
\hline Dissolved oxygen & & & & & & \\
\hline Temperatura pela manhã $\left({ }^{\circ} \mathrm{C}\right)$ & 23,97 & 23,84 & 23,53 & 23,51 & 23,51 & 23,54 \\
\hline Temperature at morning & & & & & & \\
\hline Temperatura a tarde $\left({ }^{\circ} \mathrm{C}\right)$ & 25,59 & 25,71 & 25,73 & 25,65 & 25,68 & 25,76 \\
\hline Temperature at afternoon & & & & & & \\
\hline $\begin{array}{l}\text { Condutividade elétrica }(\mu \mathrm{S} / \mathrm{cm}) \\
\text { Electric conductivity }\end{array}$ & 20,52 & 20,61 & 20,78 & 20,64 & 20,73 & 20,67 \\
\hline
\end{tabular}




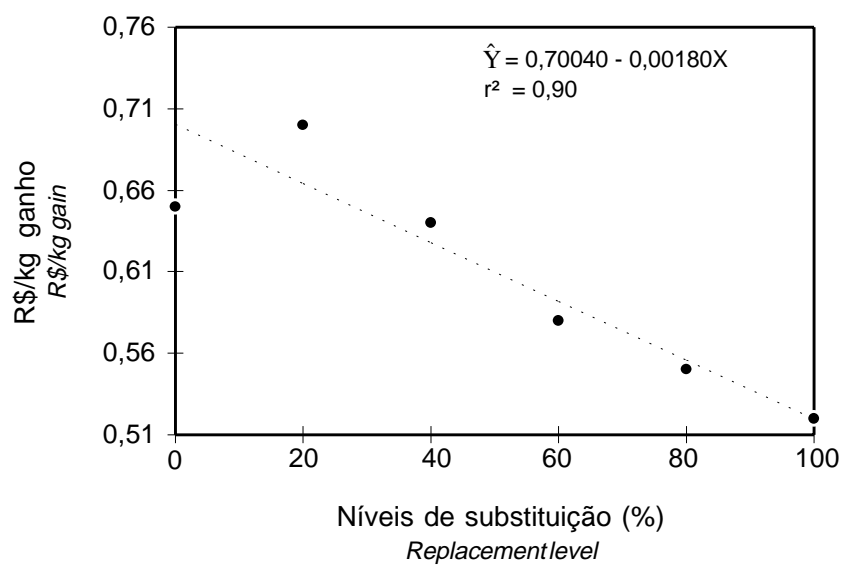

Figura 3 - Efeito dos níveis de substituição da proteína na dieta sobre o custo por kg ganho de alevinos de piavuçu.

Figure 3 - Effect of the dietary protein replacement level on the cost by $\mathrm{kg}$ of gain of piavuçu fry.

$(\mathrm{mg} / \ell)$, temperaturas pela manhã e tarde $\left({ }^{\circ} \mathrm{C}\right)$ e condutividade $(\mu \mathrm{S} / \mathrm{cm})$ de água, dos diferentes tratamentos, encontram-se na Tabela 4. Estes valores permaneceram dentro das faixas recomendadas por CASTAGNOLLI e CYRINO (1986) e TAVARES (1995), para cultivo de peixes.

\section{Conclusões}

A proteína do farelo de canola pode substituir totalmente a proteína do farelo de soja ou o farelo de canola pode ser incluído no nível de $43,12 \%$, em dietas para alevinos de piavuçu (Leporinus macrocephalus), uma vez que houve melhora de desempenho.

\section{Referências Bibliográficas}

ANDRIAN, I.F., DÓRIA, C.R.C., TORRENTE, G. et al. 1994. Espectro alimentar e similaridade na composição da dieta de quatro espécies de Leporinus (Characiformes, Anostomidae) do rio Paraná $\left(22^{\circ} 10^{\prime}-22^{\circ} 50^{\prime} \mathrm{S} / 53^{\circ} 10^{\prime}-53^{\circ} 40^{\prime} \mathrm{W}\right)$, Brasil. Revista UNIMAR, 16(suplemento 3): 97-106.

BAIDOO, S.K., CLOWES, E.L., AHERNE, F.X. 1996. The digestible energy value of canola oil for growing pigs as measured by level inclusion. Anim. Feed Sci. Technology, 62(2/4):111-119.

BARBOSA, N.D.C., CARNEIRO, D.J., MACHADO, C.R. Níveis de proteína bruta e proporções de proteína do origem animal em dietas para o desenvolvimento de piapara, Leporinus elongatus, Cuv. \& Val., 1864. In: SIMPÓSIO BRASILEIRO DE AQÜICULTURA, 9, Sete Lagoas, MG, 1996. Resumos... Sete Lagoas: ABRAq. 1996, p.96.

BELL, J.M. 1993. Factor affecting the nutritional value of canola meal: a review. J. Anim. Sci., 73(3):679-697.

BELLAVER, C., FIALHO, E.T., PROTAS, J.F.S. 1985. Radícula de malte na alimentação de suínos em crescimento e terminação.
Pesq. Agropec. Bras., 20(8):969-974.

CAPPER, B.S., WOOD, J.F., JACKSON, A.J. 1982. The feeding value for carp of two types of mustard seed cake from Nepal. Aquaculture, 29(3):373-377.

CASTAGNOLLI, N., CYRINO, J.E.P. 1986. Piscicultura nos trópicos. São Paulo: Manole. 152p.

CASTAGNOLLI, N. 1992. Piscicultura de água doce. Jaboticabal: FUNEP. 189p.

DAVIES, S.J., McCONNELL, S., BATESON, R.I. 1990. Potential of rapeseed meal as an alternative protein source in complete diets for tilapia (Oreochromis mossambicus Peters). Aquaculture, 87(1):145-154.

EUCLYDES, R.F. 1983. Manual de utilização do programa SAEG (Sistema para Análises Estatísticas e Genéticas). Viçosa: UFV. $59 \mathrm{p}$.

FURUYA, V.R.B., HAYASHI, C., FURUYA, W.M. 1997. Farelo de canola na alimentação da tilápia do Nilo (Oreochromis niloticus L.), durante o período de reversão de sexo. R. Bras. Zootec., 26(6):1067-1073.

FURUYA, W.M., RIBEIRO, R.P., HAYASHI, C. et al. Viabilidade da levedura seca, Saccharomyces cerevisae, em dietas para o cultivo em consorciação de alevinos de tilápia nilótica Oreochromis niloticus, com alevinos de piapara, Leporinus elongatus, e de piavuçu, L. macrocephalus. In: SIMPÓSIO BRASILEIRO DE AQÜICULTURA, 9, Sete Lagoas, 1996. Resumos... Sete Lagoas: ABRAq. 1996, p.81.

HARDY, R.W., SULLIVAN, C.V. 1983. Canola meal in rainbow trout (Salmo gairdneri) production diets. Can. J. Fisher. Aquat. Sci. 40(3):281-286.

HIGGS, D.A., FAGERLUND, U.H.M., McBRIDE, J.R. et al. 1983. Protein quality of Altex canola meal for juvenile chinook salmon (Oncorhynchus tshawytscha) considering dietary protein and 3,5,3-triiodo-L thyonine content. Aquaculture, 34(3):213-238.

HIGGS, D.A., McBRIDE, J.R., MARKERT, J.R. et al. 1982. Evaluation of Tower and Candle rapeseed (canola) meal and Bronowski rapeseed protein concentrate as protein supplements in practical dry diets for juvenile Chinook salmon (Oncorhynchus tshawytscha). Aquaculture, 29(1):1-31.

HILTON, J.W., SLINGER, S.J. 1986. Digestibility and utilization of canola meal in practical-type diets for rainbow trout (Salmo gairdneri). Can. J. Fisher. and Aquat. Sci., 43(6):1149-1155.

JAUNCEY, K., ROSS, B. 1982. A guide to tilapia feeds and feeding. Scotland, University of Stirling. 111p.

LIM, C., KLESIUS, P.H., HIGGS, D.A. 1998. Substituition of canola meal for soybean meal in diets for channel catfish Ictalurus punctatus. J. World Aquacult. Soc., 29(2):161-168.

MEER, M.B., MACHIELS, M.A.M., VERDEGEM, M.C.J. 1995. The effect of dietary protein level on growth, protein utilization and body composition of Colossoma macropomum (Cuvier). Aquacult. Res., 26(12):901-909.

NATIONAL RESEARCH COUNCIL - NRC. 1993. Nutrients requirements of warmwater fishes and shellfishes. Washington: Academy Press. 102p.

PEZZATO, L. E. Alimentos convencionais e não-convencionais disponíveis para indústria da nutrição de peixes no Brasil. In: SIMPÓSIO INTERNACIONAL SOBRE NUTRIÇÃO DE PEIXES E CRUSTÁCEOS, 1995, Campos de Jordão. Anais... Campos de Jordão: CBNA, 1995. p.34-52.

ROSTAGNO, H.S., SILVA, D.J., COSTA, P.M.A. et al. 1994. Composição de alimentos e exigências e nutricionais de aves e suínos (Tabelas brasileiras). Viçosa: Imprensa Universitária. 61p.

SARWAR, G., BELL, J.M., SHARBY, T.F. et al. 1981. Nutritional evaluation of meals and meal fractions derived from rape and mustard seed. Can. J. Anim. Sci., 6(13):719-733. 
SCAPINELlO, C., MOREIRA, I., MURAKAMI, A.E. et al. 1994. Substituição parcial e total da proteína bruta do farelo de soja pela do farelo de canola, para coelhos em crescimento. Rev. UNIMAR, 16:49-58. (suplemento 1)

SCHÖNE, F., KIRCHHEIM, U., SCHUMAM, W. et al. 1996. Apparent digestibility of high-fat rapeseed press cake in growing and effects on feed intake, growth and weight of thyroid and liver. Anim. Feed Sci. Techn., 629(2/4):97-110.

SILVA, A.C. Alimentação natural de quatro espécies de peixes da Família Anostomidae (Ostariophysi, Characiformes) do Rio Araguari, Bacia do Parnaíba, MG. In: ENCONTRO ANUAL DE AQÜICULTURA DE MINAS GERAIS, 6, Belo Horizonte, 1988. Resumos... Belo Horizonte: AMA, 1988, p.1.

SOARES, C.M., HAYASHI, C., FURUYA, V.R.B. et al. 1998. Farelo de canola na alimentação de alevinos de carpa-capim (Ctenopharyngodon idella V.). Acta Scientiarum (20)3:395-400.

SORREL, E.R., SHURSON, G.C. 1992. Use of canola and canola meal in swine diets reviewed. Feedstuffs, 62(14):13-16.

TAVARES, V.L.S. 1994. Liminologia aplicada à aquicultura. Jaboticabal: FUNEP. 70p.
TESKEREDIZIC, Z., HIGGS, D.A., DOSANJH, B.S. et al. 1995. Assessment of undephytinized and dephytinized rapeseed protein concentrate as sources of dietary protein for juvenile rainbow trout (Oncorhynchus mykiss). Aquaculture, 131(2):261-277.

YURKOWSKI, M., BAILEY, J.K., EVANS, R.E. et al. 1978. Acceptability of rapeseed proteins in diets of rainbow trout (Salmo gairdneri). J. Fish Res. Board Can., 35:951-962.

ZANIBONI, F.E., BARBOSA, N.D.C., TORQUATO, V.C. Tanque rede: avaliação comparativa de sua eficiência no cultivo de piau (Leporinus friderici). In: CONGRESSO BRASILEIRO DE ZOOLOGIA, 15, Curitiba, 1988. Resumos... Curitiba: UFPR, 1988. p.299.

Recebido em: 20/10/98 Aceito em: 01/06/99 